\title{
QUANTITATIVE ESTIMATION AND ANTIMICROBIAL POTENTIAL OF ETHANOL EXTRACT OF DURIO ZIBETHINUS MURR. LEAVES
}

\section{SRIDEVI CHIGURUPATI ${ }^{1 *}$, JAHIDUL ISLAM MOHAMMAD ${ }^{2}$, SHANTINI VIJAYABALAN ${ }^{1}$, NARMATHA DEVI VAIPURI ${ }^{1}$, KESAVANARAYANAN KRISHNAN SELVARAJAN ${ }^{3}$, APPALA RAJU NEMALA ${ }^{4}$}

\begin{abstract}
${ }^{1}$ Department of Pharmaceutical Chemistry, Faculty of Pharmacy, AIMST University, Semeling, 08100 Bedong, Kedah, Malaysia.
${ }^{2}$ Department of Pharmacology, Faculty of Medicine, Cyberjaya University College of Medical Sciences, Cyberjaya 63000, Malaysia.

${ }^{3}$ Department of Pharmacology and Toxicology, College of Pharmacy, University of Hail, Hail, Kingdom Saudi Arabia. ${ }^{4}$ Department of Pharmaceutical Chemistry, Sultan-Ul-Uloom College of Pharmacy, Hyderabad, Telangana - 500 034, India. Email: sridevi.phd@gmail.com.
\end{abstract}

Received: 08 May 2017, Revised and Accepted: 30 May 2017

\section{ABSTRACT}

Objectives: The current research is aimed to investigate the natural antimicrobial potential of Durio zibethinus ethanol leaves extracts (DZL).

Methods: DZL was subjected to the preliminary phytochemical screening along with a quantitative analysis of phenols and flavonoids. Minimum inhibitory concentration (MIC) and minimum bactericidal concentration (MBC) were recorded. The agar well diffusion method was used to measure the antibacterial activity against Gram-positive and Gram-negative bacteria. The microorganisms used in the study were ATCC strains of Bacillus subtilis, Enterococcus faecalis, Staphylococcus aureus, Streptococcus pyogenes, Neisseria gonorrhoeae, Pseudomonas aeruginosa, and Escherichia coli.

Results: DZL exhibited the highest MIC of $0.1 \mathrm{mg} / \mathrm{ml}$ and MBC of $0.25 \mathrm{mg} / \mathrm{ml}$ against Gram-negative bacteria, P. aeruginosa and E. coli. At MIC of $0.1 \mathrm{mg} / \mathrm{ml}$, DZL displayed significant zone of inhibition against $P$. aeruginosa and E. coli compared to gentamycin.

Conclusion: This research has shown that DZL has natural antibacterial properties against Gram-negative human pathogens.

Keywords: Durio zibethinus, Durian, Phytochemical, Quantitative analysis, Antimicrobial, Zone of inhibition.

(C) 2017 The Authors. Published by Innovare Academic Sciences Pvt Ltd. This is an open access article under the CC BY license (http://creativecommons. org/licenses/by/4. 0/) DOI: http://dx.doi.org/10.22159/ajpcr.2017.v10i9.19767

\section{INTRODUCTION}

Infections and illness caused by a microorganism such as bacteria, fungi, and viruses are a threat to patients, especially to those who have a compromised immune system. These infectious diseases have played a vital role in morbidity and mortality in those patients [1]. For many decades, utilization of antimicrobial for treating infection disease is indeed effective and has shown improvement. Regrettably, antimicrobial resistance is a global issue and a public health problem where a country's economic and social development is affected [2].

The fundamental cause of antimicrobial resistance is suspected to be the misemployment of antimicrobial in treating infectious disease. Apart from that, the food industry also plays a part in these phenomena due to selection and inclusion of resistant microorganism in the food chain. Stock breeding farms have been hefty in using antimicrobial agents and hence contribution to resistances. Constant and persistent exchanges of genetic material among microorganism have created a pool of resistance genes that are one way or another creating new pathway to cause resistance [3].

Bacteria that possess resistant gene or can multiply and survive despite the presence of two or more antibiotics are known as multidrug resistant bacteria [4]. Hence, there is a dying need for new and better antimicrobial substance that can be either as microbiostatic that is to inhibit their growth or as a microbicidal that is to kill the microorganism. Plant as sources of antimicrobial substance does provide huge advantages as they are effectual to address this issue. Furthermore, antimicrobial of plant origin produces lesser assorted side effects that commonly link to synthetic antimicrobials [1].

Leaves were the most widely used plant parts which were commonly prepared by boiling in water (decoction) and administered orally.
Stomach ailments, respiratory diseases, wounds or cuts, and muscle pains or over fatigue in women were the most common health problems treated by the identified medicinal plants [5]. The Durio zibethnius of the Bombacaceae family originated in Peninsular Malaysia, and its unique characteristics favor its widespread cultivation [6].

Studies have shown that Durian's bioactive compounds inclusive of anthocyanins, flavonoids, carotenoids, and flavanol presences in its pulp. It is evident that the levels of antioxidant and antiproliferative differ according to its ripeness. Almost all parts such as the fruit, pulp, leaves, and roots of Durian are used traditionally as remedies for many diseases [7]. Durio zibethinus leaf (DZL) is documented to be used traditionally by the Kensie tribe in Kedah, Malaysia as fever and influenza remedy by mixing the macerated leaves in bathing water [8].

This study targets to analyze the presence of various phytochemical constituents qualitatively and quantitatively and screen the antimicrobial potential of $D$. zibethinus leaves against common human pathogens.

\section{METHODS}

\section{Sample collection}

The fresh and un-infested leaves of plant D. zibethinus were collected from Baling, 09100, Kedah, Malaysia. They were identified with herbarium voucher specimen accession number (AIMST/FOP/03).

\section{Preparation of extract}

The gathered DZL were rinsed in running water and dried under the sun for not $<2$ days, to avoid chemical decomposition. After drying, the leaves were ground by Waring Blender. The extraction was done by percolation procedure utilizing soxhlet apparatus and a single solvent system, $70 \%$ ethanol. The leaves were weighed at $200 \mathrm{~g}$, then sliced into 
little pieces and set for hot percolation. The process was carried out until the green color of the solvent turns almost colorless in the soxhlet tube. The extract solution attained was filtered through a muslin cloth to separate the residue and filtrate. The residue was further adjusted to the required concentration. The residual extraction was repeated until a clear colorless supernatant liquid was acquired. The filtrate was evaporated using a rotary evaporator [9].

\section{Qualitative phytochemical screening}

Preliminary phytochemical screening of ethanol extract of DZL to distinguish the presence of phytoconstituents such as gum, anthocyanin, starch, monosaccharides, reducing sugar, carbohydrates, amino acids, protein, tannin, glycoside, phenol, mucilage steroid, alkaloid, flavonoid, and saponin was carried out using the standard biochemical techniques [10].

\section{Quantitative phytochemical screening}

\section{Determination of total phenolic content}

Extract phenolic content was identified by modified spectrophotometric method [11]. The sample was prepared in various concentrations ranging from $0.005 \mathrm{mg} / \mathrm{ml}$ to $0.02 \mathrm{mg} / \mathrm{ml}$. The reaction was composed of the sample $(100 \mu \mathrm{l})$, Folin-Ciocalteu's reagent $(100 \mu \mathrm{l})$ and $2.5 \%$ sodium carbonate solution $(2 \mathrm{ml})$ and it was kept for incubation at room temperature for 30 minutes. The absorbance was taken at $750 \mathrm{~nm}$. The procedure was repeated for standard Gallic acid (GA). The calibration curve was constructed. From the measured absorbance value, the phenolic concentration was expressed as GA equivalent in $\mathrm{mg} / \mathrm{g}(\mathrm{GA} \mathrm{mg} / \mathrm{g})$.

\section{Determination of total flavonoid content}

Extract flavonoid content was identified by modified spectrophotometric method [12]. The sample was prepared in various concentrations, ranging from $0.01 \mathrm{mg} / \mathrm{ml}$ to $0.1 \mathrm{mg} / \mathrm{ml}$. The reaction was composed of the sample $(1 \mathrm{ml}), 30 \%$ ethanol $(10 \mathrm{ml})$, and $10 \%$ aluminium chloride solution $(0.7 \mathrm{ml})$ and it was kept for incubation at room temperature for 6 minutes. Sodium hydroxide solution $(1 \mathrm{M}, 10 \mathrm{ml})$ was added and the volume was made up to $25 \mathrm{ml}$ with $30 \%$ ethanol and left for 10 minutes. The absorbance was taken at $450 \mathrm{~nm}$. The procedure was repeated for standard Rutin (RU). The calibration curve was constructed. From the measured absorbance value, the flavonoid concentration was expressed as $\mathrm{RU}$ equivalent in $\mathrm{mg} / \mathrm{g}(\mathrm{RU} \mathrm{mg} / \mathrm{g})$.

\section{Antibacterial activity}

McFarland 0.5 standard

The standard was prepared by adding $0.5 \mathrm{ml}$ of $1.175 \%$ barium chloride solution to $99.5 \mathrm{ml}$ of $1 \%$ sulfuric acid. The tubes were sealed and kept under a dark condition at room temperature. The standard gives turbidity $(\mathrm{OD}=7$ ) practically identical to that of a bacterial suspension containing $1.5 \times 10^{8}$ colony-forming units (CFU) $/ \mathrm{ml}$ or $1.5 \times 10^{5} \mathrm{CFU} / \mu \mathrm{l}$. The turbidity of the inoculums suspensions was compared by observing the black lines through the suspension [13].

Determination of minimum inhibitory concentration (MIC) and minimum bactericidal concentration (MBC)

The test tube dilution was used to determine the MIC. $1 \mathrm{ml}$ of nutrient broth was added into sterile test tubes. $1 \mathrm{ml}$ of $1 \mathrm{mg} / \mathrm{ml}$ test solution was transferred to one tube and serially diluted ranging from $0.03125 \mathrm{mg} / \mathrm{ml}$ to $0.5 \mathrm{mg} / \mathrm{ml}$. Following that, $0.1 \mathrm{ml}$ of inoculums was inoculated, and the tubes were incubated at $37^{\circ} \mathrm{C}$ for $24 \mathrm{hrs}$. The growth in the tubes was observed visually for turbidity. The MIC was determined by the lowest concentration of extract that suppressed bacterial growth which was determined by the absence of turbidity in the broth [14].

The MBC was determined by comparing the number of viable bacteria or inoculums with the initial number. All tubes from the MIC study that showed no visible turbidity were serially diluted and spread onto nutrient agar plates for viable cell counting or CFU. The plates were incubated at $37^{\circ} \mathrm{C}$ for $24 \mathrm{hrs}$. The $\mathrm{MBC}$ was recorded as the lowest concentration of extract that killed at least $99.99 \%$ of the initial bacterial number [15].

\section{Agar well diffusion method}

The screening for antibacterial activity was conducted using agar well diffusion assay [16]. The extract were tested for their antibacterial activities against three Gram-negative bacteria (Neisseria gonorrhoeae, Pseudomonas aeruginosa, and Escherichia coli) and four Gram-positive bacteria (Bacillus subtilis, Enterococcus faecalis, Staphylococcus aureus, and Streptococcus pyogenes). The bacterial inoculums were uniformly spread by sterile cotton swab on Muller Hinton agar plates. A voume of $50 \mu \mathrm{l}$ of extracts were added to each of the 4 wells $(12 \mathrm{~mm}$ diameter holes cut in the agar, $20 \mathrm{~mm}$ apart from one another). The plates were incubated for $24 \mathrm{hrs}$ at $36^{\circ} \mathrm{C} \pm 1^{\circ} \mathrm{C}$, under aerobic conditions. After the incubation period, bacterial growth was observed and the inhibition of the bacterial growth was measured in mm. The referred antibiotic, gentamicin was used as positive control and $10 \%$ dimethyl sulfoxide as negative control [17].

\section{RESULTS}

Results of phytochemical screening presented in Table 1 evidence the presence of various phytoconstituents such as glycosides, mucilage, steroid, carbohydrate, flavonoid, alkaloid, and phenol.

The extract phenolic content was identified in terms of GA from the standard GA curve as illustrated in Fig. 1a and 1b. A high correlation $\left(r^{2}=0.8104\right)$ among concentration and as the absorbance was depicted from the standard calibration curve which showed the linear regression equation (RE) of $y=0.0032 x+0.044$. Thus, total phenolic content of DZL is $1.80 \mathrm{mg} / 100 \mathrm{~g}$ of crude extract (Fig. 1).

The flavonoid content present in the DZL was identified in terms of RE from the standard RU curve as illustrated in Fig. $2 \mathrm{a}$ and $2 \mathrm{~b}$. The linear $\mathrm{RE}$ of $\mathrm{y}=0.0004 \mathrm{x}+0.0067$ and a high degree of correlation $\left(\mathrm{r}^{2}=0.9723\right)$ among concentration and the absorbance was depicted from the

Table 1: Qualitative phytochemical analysis of DZL

\begin{tabular}{lc}
\hline Phytochemical constituents & DZL \\
\hline Alkaloids & + \\
Flavonoids & + \\
Saponins & - \\
Steroids & + \\
Gums & - \\
Mucilage & + \\
Glycosides & + \\
Tannins & - \\
Proteins & - \\
Amino acids & - \\
Carbohydrates & + \\
Reducing sugar & + \\
Monosaccharides & - \\
Starch & - \\
Anthocyanins & - \\
Phenols & + \\
\hline
\end{tabular}

+: Present, -: Absent, DZL: Durio zibethinus ethanol leaves extracts

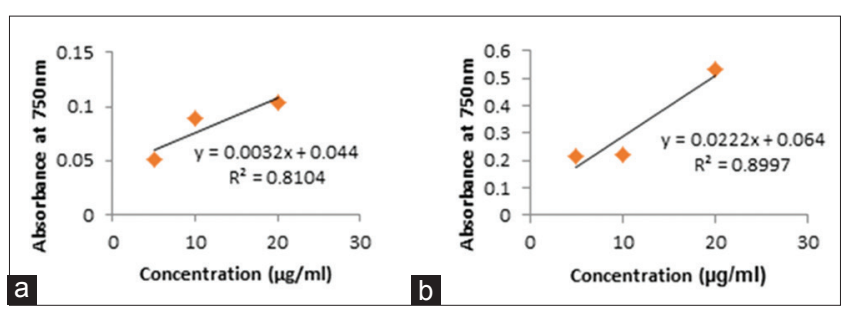

Fig. 1: Standard curve of gallic acid (a) and Durio zibethinus ethanol leaves extracts (b) 
calibration curve. Thus, total flavonoid content of DZL is $1.34 \mathrm{mg} / 100 \mathrm{~g}$ of crude extract (Fig. 2).

The antimicrobial assay of DZL was tested against four Gram-positive and three Gram-negative ATCC bacterial strains. The results illustrated in Table 2 revealed the MIC and MBC of DZL. DZL exhibited the highest MIC of $0.1 \mathrm{mg} / \mathrm{ml}$ and MBC of $0.25 \mathrm{mg} / \mathrm{ml}$ against Gram-negative bacteria, $P$. aeruginosa and E. coli. At MIC of $0.1 \mathrm{mg} / \mathrm{ml}$, as portrayed in Table 3, DZL displayed significant zone of inhibition against P. aeruginosa, $11.2 \pm 0.76 \mathrm{~mm}$ and E. coli, $12.0 \pm 1.00 \mathrm{~mm}$ compared to gentamycin $12.3 \pm 1.15 \mathrm{~mm}$ and $13.7 \pm 0.58 \mathrm{~mm}$, respectively (Figs. 3 and 4). The extract showed minimal antimicrobial activity against $S$. aureus and $N$. gonorrhoeae. All the data were expressed in mean \pm standard deviation $(\mathrm{n}=3)$.

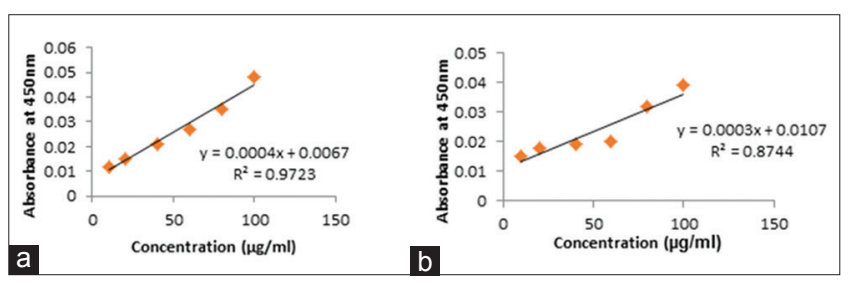

Fig. 2: Standard curve of rutin (a) and Durio zibethinus ethanol leaves extracts (b)

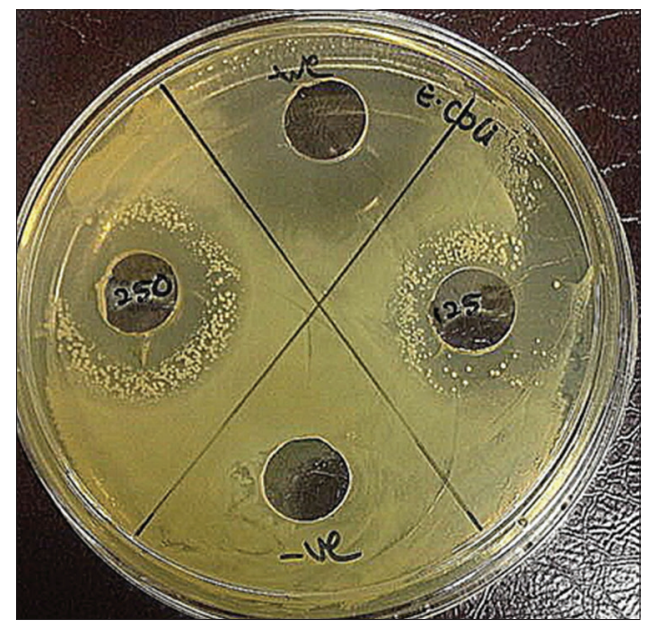

Fig. 3: Zone of inhibition of Durio zibethinus ethanol leaves extracts against Escherichia coli

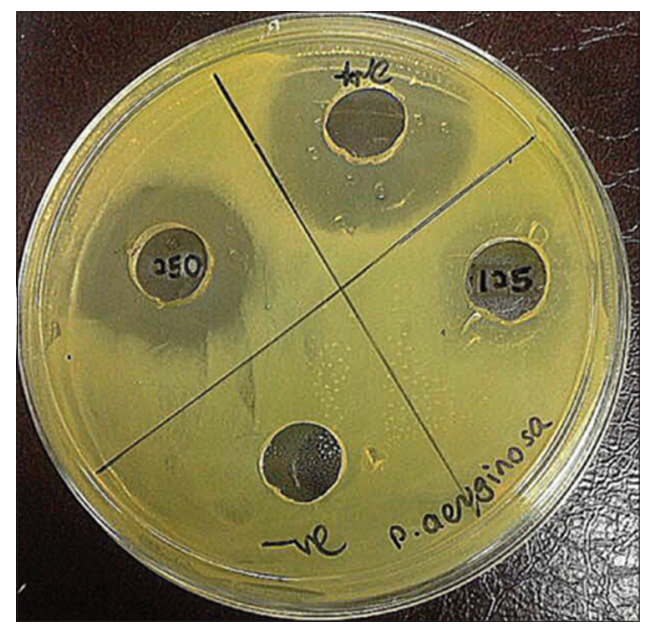

Fig. 4: Zone of inhibition of Durio zibethinus ethanol leaves extracts against Pseudomonas aeruginosa

\section{DISCUSSION}

Medicinal plants possessed therapeutic values lie in the phytoconstituents that cause unequivocal human pharmacological action [18]. The plants are the indispensable source of an endless number of antimicrobial compounds. A few phytochemical compounds such as polyphenols, flavonoids, phenolic, tannins, terpenoids, sesquiterpenes, and many more other constituents are known antimicrobial compounds against an extensive range of microorganisms. The study showed DZL is a potential wellspring of Gram-negative antimicrobial agent when compared to Gram-positive bacterial agents. The presence of various phytoconstituents, especially flavonoid, phenol, and alkaloid could be characteristic factor for the antibacterial properties.

The antimicrobial action of the extract may be credited to the high flavonoid content present, which has been accounted for the inhibition of nucleic acid synthesis along with other metabolic activities [19]. Flavonoids have likewise been accounted for to inhibit spore germination of plant pathogens [20]. The phenolic compounds with the side chain of $\mathrm{C}_{3}$ at a lower level of oxidation and absences of oxygen have reported being responsible for the antimicrobial assay. The partial hydrophobic nature of phenolic compounds also an antimicrobial factor. The toxicity mechanism of polyphenols against pathogens could be related to inhibition of hydrolytic enzymes, especially proteases or different interactions that inactivate the microbial adhesions, cell envelope transport proteins, and non-specific interactions with carbohydrates [21].

\section{CONCLUSION}

From our research, it is concluded that the DZL has the essential phytoconstituents that attributed to the antimicrobial activity. The extract able to act against various human pathogens which might be due to the high flavonoid and phenolic content present. However, further study is needed to isolate and characterized the active compounds present in DZL and conceivably their biological mechanisms to develop the potent antimicrobial drug.

Table 2: The results of MIC and MBC of DZL

\begin{tabular}{lll}
\hline Microorganisms & DZL & \\
\cline { 2 - 3 } & $\begin{array}{l}\text { MIC } \\
\mathbf{( m g / m L )}\end{array}$ & $\begin{array}{l}\text { MBC } \\
\mathbf{( m g / m L})\end{array}$ \\
\hline Bacillus subtilis (ATCC 11774) & 0.125 & 0.5 \\
Enterococcus faecalis (ATCC 29212) & 0.25 & 1.0 \\
Staphylococcus aureus (ATCC 29213) & 0.125 & 0.5 \\
Streptococcus pyogenes (ATCC 19615) & 0.125 & 0.5 \\
Neisseria gonorrhoeae (ATCC 43069) & 0.1 & 0.25 \\
Pseudomonas aeruginosa (ATCC 10145) & 0.1 & 0.25 \\
Escherichia coli (ATCC 10799) & 0.1 & 0.25 \\
\hline
\end{tabular}

MIC: Minimum inhibitory concentration, MBC: Minimum bactericidal concentration, DZL: Durio zibethinus ethanol leaves extracts

Table 3: The zone of inhibition of DZL

\begin{tabular}{lll}
\hline Microorganisms & \multicolumn{2}{l}{$\begin{array}{l}\text { Zone of inhibition } \\
(\mathbf{m m}, \mathbf{0 . 2 5} \mathbf{~ m g} / \mathbf{m L}) \pm \text { SD }\end{array}$} \\
\cline { 2 - 3 } & $\mathbf{D Z L}$ & Gentamicin \\
\hline Bacillus subtilis & $7.7 \pm 0.58$ & $14.0 \pm 1.00$ \\
Enterococcus faecalis & $7.7 \pm 1.15$ & $14.3 \pm 0.58$ \\
Staphylococcus aureus & $3.0 \pm 1.00$ & $14.0 \pm 1.00$ \\
Streptococcus pyogenes & $7.7 \pm 0.5$ & $10.7 \pm 0.58$ \\
Neisseria gonorrhoeae & $5.71 \pm 0.58$ & $14.3 \pm 1.15$ \\
Pseudomonas aeruginosa & $11.2 \pm 0.76$ & $12.3 \pm 1.15$ \\
Escherichia coli & $12.0 \pm 1.00$ & $13.7 \pm 0.58$ \\
\hline
\end{tabular}

All the data were expressed in mean \pm SD $(n=3)$. DZL: Durio zibethinus ethanol leaves extracts, SD: Standard deviation 


\section{ACKNOWLEDGMENT}

The authors are thankful to AIMST University for their support and facilities provided.

\section{REFERENCES}

1. Tawfick MM, Gad SA. In vitro antimicrobial activities of some Egyptian plants essential oils with medicinal applications. Am J Drug Discov Dev 2014;4(1):32-40.

2. Sridevi CH, Kannan MM, Abhinayani G, Sravya N. Designing and biological evaluation of new benzimidazole compounds. Chem Sci Transl 2013;2(3):922-6.

3. Nagyzbekkyzy E, Abitayeva G, Anuarbekova S, Shaikhina D, Li K, Shaikhin S, et al. Investigation of acid and bile tolerance, antimicrobial activity and antibiotic resistance of Lactobacillus strains isolated from Kazakh dairy foods. Asian J Appl Sci 2016;9(4):143-58.

4. Elsayed A, Mohamedin A, Ata T, Ghazala N. Molecular characterization of multidrug resistant clinical Escherichia coli isolates. Am J Biochem Mol Biol 2016;6(3):72-83.

5. Olowa LF, Torres MA, Aranico EC, Demayo CG. Medicinal plants used by the higaonon tribe of Rogongon, Iligan city, Mindanao, Philippines. Adv Environ Biol 2012;6(4):1442-9.

6. Ashraf MA, Maah MJ, Yusoff I. Estimation of antioxidant phytochemicals in four different varieties of durian (Durio zibethinus Murray) fruit. Middle East J Sci Res 2010;6(5):465-71.

7. Haruenkit R, Poovarodom S, Vearasilp S, Namiesnik J, Sliwka-Kaszynska M, Park YS, et al. Comparison of bioactive compounds, antioxidant and antiproliferative activities of Mon Thong durian during ripening. Food Chem 2010;118(3):540-7.

8. Mohammad NS, Milow P, Ong HC. Traditional medicinal plants used by the Kensiu tribe of Lubuk Ulu Legong, Kedah, Malaysia. Stud Ethno Med 2012;6:149-53.

9. Bindu AR, Rosemary J, Akhila S. Antimicrobial activity screening of M. minuta extracts. Int J Pharm Pharm Sci 2014;6(10):581-3.
10. Prabhavathi RM, Prasad MP, Jayaramu M. Studies on qualitative and quantitative phytochemical analysis of Cissus quadrangularis. Pelagia Res Libr Adv Appl Sci Res 2016;7(4):11-7.

11. Murthy NK, Pushpalatha KC, Joshi CG. Antioxidant activity and phytochemical analysis of endophytic fungi isolated from Lobelia nicotianifolia. J Chem Pharm Res 2011;3(5):218-25.

12. Zuccaro L, Satyanarayana B, Naidu MT. Phytochemical screening for secondary metabolites in Boswellia serrata Roxb and Wrightia tinctoria (Roxb.). R Br Notulate Sci Biol 2014;6(4):474-7.

13. Ataee RA, Mehrabi-Tavana A, Hosseini SM, Moridi K, Zadegan MG. A method for antibiotic susceptibility testing: Applicable and accurate. Jundishapur J Microbiol 2012;5(1):341-5.

14. Chigurupati S, Fuloria NK, Fuloria S, Karupiah S, Veerasamy R, Nemala AR, et al. Synthesis and antibacterial profile of novel azomethine derivatives of $\beta$-phenylacrolein moiety. Trop J Pharm Res 2016;15(4):821-6.

15. Chandrappa MS, Harsha R, Dinesha R, Gowda SS. Antibacterial activity of Coleus aromaticus leaves. Int J Pharm Pharm Sci 2010;2(3):63-6.

16. Chigurupati S, Veerasamy R, Nemala AR, Gowlikar A, Lee KS. Designing and in-vitro antibacterial activity of new benzotriazole compounds. World J Pharm Pharm Sci 2014;3(3):1645-51.

17. Sridevi CH, Balaji K, Naidu A, Sudhakaran R. Synthesis of some phenyl pyrazolo benzimidazolo quinoxaline derivatives as potent antimicrobial agents. J Chem Pharm Sci 2010;3(1):13-6.

18. Shah SM, Ali-Khan F, Shah SM, Chishti KA, Pirzada SM, Khan MA, et al. Evaluation of phytochemicals and antimicrobial activity of white and blue capitulum and whole plant of Silybum marianum. World Appl Sci J 2011;12(8):1139-44.

19. Cushnie TP, LambAJ, Lamb C, He XZ, Reddy JT, Jerala R. Antimicrobial activity of flavonoids. Int J Antimicrob Agents 2005;26(5):343-56.

20. Harborne JB, Williams CA. Advances in flavonoid research since 1992. Phytochemistry 2000;55(6):481-504.

21. Pyla R, Kim TJ, Silva JL, Jung YS. Enhanced antimicrobial activity of starch-based film impregnated with thermally processed tannic acid, a strong antioxidant. Int J Food Microbiol 2010;137(2-3):154-60. 